\title{
THEORETICAL AND PRACTICAL FOUNDATIONS FOR INNOVATIVE IMPLEMENTATION OF PSYCHOTHERAPEUTIC CONFRONTATIONAL SUPERVISION: TOWARDS A CONCEPT OF COGNITIVE PSYCHOTHERAPY IN HIGHER EDUCATION INSTITUTIONS
}

\begin{abstract}
Yuri Vitomski ${ }^{1}$, Stepan Bondarenko ${ }^{2}$
${ }^{1}$ Ph.D. in Psychology, Associate Professor at the Department of Criminal Law, Procedure and Criminalistics, Kyiv Institute of Intellectual Property and Law, National University Odessa Law Academy, Member of the National Psychological Association of Ukraine", Member of the specialised academic council K 26.130.02 - "Psychological Sciences" at the KROK University, Kyiv, Ukraine, e-mail: u.vitomskyi@gmail.com, ORCID: https://orcid.org/0000-0003-3094-5104

${ }^{2}$ Deputy of Higher Education at the Bachelor's Degree, Kyiv Institute of Intellectual Property and Law, National University "Odessa Law Academy", Senior Methodologist of the Department of Criminal Law, Procedure and Criminalistics, Kyiv, Ukraine, e-mail: bondarenko.stephan@ukr.net, ORCID: https://orcid.org/0000-0001-8328-5117
\end{abstract}

Abstract. In this article some theoretical aspects of psychotherapeutic confrontational suggestion. The similarities between of certain provisions of psychotherapeutic confrontational suggestion and cognitive psychotherapy. It was also found that confrontational psychotherapeutic suggestion and traditional cognitive psychotherapy have in common. Cognitive psychotherapy is the priority of working with dysfunctional thoughts in students. It is stated that psychotherapy is a way of learning and education. It has been shown that unlike traditional cognitive psychotherapy, in psychotherapeutic confrontational suggestion the connection between feeling, behaviour and thought is not postulated, but presented as a hypothesis. It is noted that when psychotherapeutic confrontational suggestion is implemented, the client (student) forms adaptive beliefs that gradually destroy dysfunctional thoughts. It is shown that psychotherapeutic confrontational suggestion is an essential component of multimodal suggestive psychotherapy.

Keywords: suggestion, psychotherapy, psychotherapeutic confrontational suggestion, cognitive psychotherapy, dysfunctional thoughts, belief correction, multimodal suggestive psychotherapy, psychology.

JEL Classification: I10, I21, I23, I25

Formulas: 0; fig.: 0; tabl.: 0; bibl.: 7

Introduction. Psychotherapeutic confrontational suggestion (PCS) is a very relatively new area of suggestive psychotherapy for people with all kinds of neurotic disorders.

Primarily we are talking about clients with anxiolytic-phobic, obsessivecompulsive and somatoform disorders. PCS complements and significantly expands the possibilities of traditional domestic suggestive psychotherapy.

One of the main goals of PCS is to have a sanogenic influence on the cognitive sphere of the person. Numerous publications on psychotherapy have repeatedly pointed to the fact that in well adapted individuals, cognitive strategies for perceiving reality change with their new experiences. Their thinking is characterized by plasticity and versatility.

Thoughts that prevent a person from coping with life's various situations, are called dysfunctional or maladaptive. They are most often associated with inadequate emotional reactions and all kinds of abnormal behaviour.

Processing dysfunctional thoughts and transforming them into adaptive ones is one of the main tasks of psychotherapeutic work in general, and PCS in particular. 
The following can be added to the basics of psychotherapeutic confrontational suggestion [5]: 1 . There are general scientific principles and worldview ideas that are antagonistic to dysfunctional thoughts; 2 . These ideas-principles can be instilled in a person by heterogeneous suggestion; 3 . The collision of suggested sanogenic ideasprinciples with dysfunctional thoughts provokes the phenomenon of cognitive dissonance with the subsequent correction of dysfunctional thoughts.

In the process of practical work it became necessary to create a more fundamental theoretical framework for PCS. In this connection in this regard, a highly relevant area of scientific research is to establish the commonalities and differences between PCS and its main prototypes.

This article presents a comparative analysis of PCS and traditional cognitive psychotherapy.

Literature Review. Psychotherapeutic confrontational suggestion and its theoretical origins is a relatively new area of research and the number of publications devoted to this topic is very small.

The previously presented works outline only the basic ideas of confrontational suggestion, methodological recommendations for its implementation, and the relationship between PCS and rational psychotherapy. These publications contain virtually no data on the relationship of PCS to the leading psychotherapeutic trend, such as cognitive psychotherapy.

Numerous publications are devoted to cognitive (or rather, cognitive-behavioral) psychotherapy itself, its theoretical foundations, principles and methods of exposure. First of all we are talking about the works of A. Beck, A. Ellis, D. Prohazka, D. Norcross, V. Guidano, G. Liotti, M. Mahoney, K.S. Dobson, A. Lazarus [7].

Cognitive therapy of Aron Beck and rational-emotional therapy of Albert Elis (being basic directions!) are based on integration of principles of learning theory, information theory, as well as principles of correction of dysfunctional cognitive processes.

James Prohazka and John Norcross formulated the main features of cognitivebehavioural psychotherapy are [7]: 1. Dissatisfaction with clinical theory and findings psychoanalysis; 2. Cognitive orientation - helping clients is about cognitive orientation - helping clients is about teaching them how to think because all problems are based on impaired thinking; 3. Empiricism - theory must conform to the principles of objective science and no myths about human nature are acceptable;

4. Problem-orientation - focus on solving of concrete problems of relations rather than working through deep personal traumas; 5. Psychotherapy is a form of training, with the therapist acting as a teacher and a scholar; 6. Psychotherapy is a form of education and the therapist has the roles of a teacher and a scholar; 7. An obligatory element of the treatment is the homework of the client. 8. An obligatory part of the treatment is the homework of the client.

The importance of the ideas of cognitive-behavioural psychotherapy for the emergence of modern psychotherapy.

The significance of cognitive-behavioural psychotherapy ideas for the formation of modern psychotherapy determines 
The relevance of using its ideas and methodology for constructing theoretical basis of psychotherapeutic confrontational suggestion.

Aims. To identify those main provisions of cognitive psychotherapy which can be used in innovative construction of the theoretical basis of psychotherapeutic confrontational suggestion.

Methods. The research was based on comparative method, analytical study method and theoretical generalization of existing scientific concepts method.

Results. According to the main tenets of cognitive psychotherapy, emotional and behavioural problems are related to impaired cognitive processes.

Cognitive psychotherapists traditionally distinguish two levels of cognitive processes: 1. "Automatic thoughts and images, which are connected with the processing of current information and are, in a sense, a reaction to what is happening at the moment; 2. Beliefs, attitudes, beliefs, which are the system of deep notions of an individual about himself or herself and the world around, which record all his past experience.

The main characteristics of automatic thoughts are They are involuntary, fleeting, and poorly conscious.

They are experienced as entirely plausible. Their truthfulness is not is not questioned.

Automatic thoughts with a specific direction and content predominate in affective disorders. In cognitive psychotherapy, automatic thoughts are regarded as the source of most emotional and behavioural disorders.

It should be noted that, in the special literature on cognitive psychotherapy, automatic thoughts are always presented as something negative.

However, their main characteristics, namely automatism, ego-synchrony, poor awareness, and difficulty of accessibility and sustainability, do not mean that they are dysfunctional. All spontaneous thoughts on a given occasion have these characteristics. In other words, the above-mentioned characteristics are necessary, but not sufficient, conditions for stating that automatic thought is pathogenic.

Their notion of "dysfunctionality" can be defined only situationally, as a result of the coincidence of multiple conditions.

The same thought can be both adaptive and maladaptive. For example, the absence of a reciprocal greeting from of a classmate may, in fact, be an indication of his or her an extremely unfriendly attitude towards an acquaintance. And the latter's thought the latter's "he can't stand me", is not dysfunctional, is consistent with the situation and provides an incentive to choose wiser interaction tactics.

The idea that "I mean nothing to her/him" may be fully consistent with the situation that has arisen. Appropriate to the situation and encourage the rejected person to the rejected person to act in a very constructive way [3]. The thought of a dangerous illness, in one case, provokes a hypochondriacal disorder, in the other it allows the necessary examinations in time, to take appropriate measures and to stop at an early stage dangerous disease in its early stages.

These examples show that "dysfunctionality" is not is not a necessary attribute of automatic thought, but only one possible consequences of it, as well as, evaluative 
characteristics that give an idea of the degree of pathogenicity of thought at a particular time and in a particular situation.

In other words, "dysfunctionality" - is variable and situationally determined.

The degree of negative impact of automatic thought depends on many factors: the mental and physiological state of the person at the moment the thought occurred, the degree to which it concentration, the person's system of ideas about him- or herself and the world view, etc. One and the same automatic thought for different people or even the same person can be adaptive or maladaptive, at times maladaptive. This ambiguity should be defined as situational dysfunctionality as situational dysfunctionality. It is quite logical, therefore, to introduce the concept of situational dysfunctionality.

It is logical to introduce the notion of the degree of dysfunctional thought as a variable, which makes it possible to evaluate the usefulness or detrimentalness of automatic thought at a given point in time for a given individual.

All of the above considerations may well be applied to the more deeper cognitive formations such as beliefs, attitudes, "thought-forming" multimodal images, etc. In cognitive psychotherapy subdivides these underlying cognitions into intermediate and intermediate cognitive psychotherapy classifies these underlying formations into intermediate and basic formations [7]. Sometimes compensatory beliefs are sometimes subdivided into intermediate and basic beliefs a kind of reactive formations that serve as a defense against threats from the underlying negative beliefs, which are based on the underlying negative beliefs.

It is quite clear that this classification is very tentative and approximate, since compensatory beliefs are distinguished by the mechanism of their formation, and intermediate and basic beliefs are classified according to their degree of depth. The traditional scheme is: automatic thoughts - intermediate beliefs - basic beliefs is also arbitrary. This gradation is only tentative and helps the therapist to decide on one or another form of psychotherapeutic intervention form of psychotherapeutic intervention. It is not suitable for research purposes. It is not suitable for research purposes. It is hardly possible to draw a precise the boundary where automatic thoughts end and intermediate or basic beliefs begin intermediate or underlying beliefs [4].

Rather, one must speak of a certain continuum of "depth" (or resistance to all sorts of influences) of this or that thought.

The processing of dysfunctional thoughts is done in cognitive psychotherapy is carried out in steps. First of all the client is introduced to the general model of psychotherapy. The client is made aware of the limitations of knowledge, the close link between thought, feeling and action actions, and about processes which lead to distortions of thoughts. In the work of A. Kholmogorova and Garanyan [6] give an example client instruction. It looks as follows: "Usually between a specific external situation and an emotional reaction to (e.g., a 'gratuitous' disorder), there is a there is usually an interval, the so-called 'gap' during which "there are necessarily some thoughts which are called..."automatic" thoughts. They are involuntary, incoherent and flicker in the mind at a very high speed. But they are potentially "they're 
potentially conscious, and in order to understand your reactions, it's very important to understand your reactions."

What is striking in this passage is the abundance of imperative statements "there's usually a gap", "there's bound to be "there are thoughts", "they flicker around in your head at a high rate of speed", "it's important to learn to pick them up". In essence, the client is indoctrinated with the idea that between an event and an emotional reaction to it, the client is led to believe between the event and his or her (the client's) emotional reaction to it, a thought is bound to flit by. So whether this is true or not, in most cases it is impossible to check is impossible to verify.

However, under the influence of the authority of the therapist as well as some the client "remembers" an appropriate thought, as well as other factors case and receives positive reinforcement from the therapist [3]. When both participants in psychotherapy want to discover an automatic thought, they are bound to discover it, even where it was not there in the first place. This self-deception in itself is not too dangerous. In fact, the process of finding "automatic thought" allows you to get close to the client's real pathogenic beliefs.

The presence in cognitive psychotherapy of a significant a significant element of suggestion is evident in the traditional questions which the psychotherapist asks the client at the stage of revealing automatic thoughts. For example: "What flashed through your mind at that moment? (As if it was bound to "flicker"!); "What do you think you were thinking?" (Was I thinking of something?!);

Is it possible that you were thinking this or that (according to the therapist's the therapist's guess)? (This directly suggests a ready-made version, with which the client, in a trusting relationship with the therapist the therapist is likely to agree!).

The use of suggestion in cognitive psychotherapy (even if its existence is not acknowledged by cognitive psychotherapists themselves) is not a random phenomenon. Suggestion (of course, in reasonable in reasonable quantities!) enables psychotherapy to be compressed and made more "focused" directed and "concentrated" [4]. Analysis of transcripts of psychotherapeutic sessions gives reason to assert that the correction of dysfunctional thoughts goes more quickly with the active use of heterogeneous suggestion.

An overview of the main stages and techniques of cognitive psychotherapy shows that in the process it teaches the client the skills of recognising, systematically recording, evaluating dysfunctional thoughts and then confronting them and, as a consequence, correcting them consequently, correction. A person who has mastered such skills begins to treat any thought, any idea as only a as a hypothesis that needs to be tested. Hypothesis testing allows to detect logical errors in judgement, for example, overgeneralisations with other students.

Various techniques are used for the correction of logical errors. For example [2]: deliberate exaggeration - taking an idea to the extreme or even to the total absurdity; Calculating the probability of the worst possible version of events; "Scaling" - to soften the extremes of judgement by softening the extremes of judgement by introducing "gradation"; re-attribution - reconsidering perceptions of the contribution 
of internal and external factors in what happened, and with it a revision of assessment of the positive and negative consequences of maintaining or changing beliefs.

Assessing the positive and negative consequences of maintaining or changing beliefs. All of these techniques allow the therapist and the client to explore to find and find more logical alternatives to dysfunctional inferences.

In order to consolidate a positive result, a process of confrontation with maladaptive thoughts needs to be brought to automaticity.

Logical confrontation is achieved through the analysis of consequence analysis, internal coping dialogue, practicing the skill of formulating a contrary view, etc.

Outside whether or not Socratic dialogue, the technique of is used, or any other technique, the result is that the client is taught to think more constructively. And all cognitive psychotherapy essentially boils down to a specific process of learning through a new "sanogenic logic" [1].

The behavioural techniques which are actively the behavioural techniques that are actively used, only serve to confirm of the usefulness and correctness of the acquired knowledge.

All of the above makes it possible to determine which of the statements of traditional cognitive psychotherapy can be borrowed cognitive psychotherapy can be borrowed to develop the theoretical foundations of psychotherapeutic confrontational suggestion. The first is the idea that maladaptive behaviour and negative emotions can be overcome by targeting the cognitive sphere of the individual.

Dysfunctional thoughts arise as a result of erroneous, distorted assessment of events and situations, and therefore a change in thinking inevitably leads to a change in perception of the world and, consequently, behaviour. For to transform maladaptive thoughts into adaptive ones the use of psychotherapeutic persuasion.

Psychotherapeutic intervention should not only target individual dysfunctional beliefs, but on the client as a whole the client's personality as a whole. The whole process of psychotherapy should be oriented towards to solve the problem. The question of why it arises is secondary [5]. The client is provided with the necessary and practically relevant information and, after a little bit of training, the client draws his own conclusions. Thus, psychotherapy becomes a way of teaching the "right" thinking. In doing so, the psychotherapist plays the role of as a natural scientist who shares with the other person his scientifically grounded knowledge of the world and his hypotheses as to the origins of the illness.

Discussion. In the future, a comparative analysis of methodological provisions of psychotherapeutic confrontational suggestion and short-term multimodal psychotherapy by A. Lazarus, and on the basis of this analysis to develop general theoretical positions of multimodal suggestive psychotherapy.

Conclusions. Some of the theoretical positions of cognitive psychotherapy (CP) can be used in the development of theoretical foundations of psychotherapeutic confrontational psychotherapy (PCS). It was found that common for PCS and traditional $\mathrm{CP}$ is the priority of work with dysfunctional thoughts.

It is shown that purposeful change of human thinking leads to correction of negative emotions and maladaptive behaviour. 
Psychotherapeutic interventions should be aimed both at specific dysfunctional beliefs and at the client's personality as a whole the client's personality as a whole.

Psychotherapy is a way of teaching and educating the individual. In contrast to traditional CP, in PCS, the connection between feeling, behavior and thought is not postulated, but is presented as a hypothesis PCS does not use the concepts of "automatic thought", intermediate and basic non-adaptive.

Author contributions. The authors contributed equally.

Disclosure statement. The authors do not have any conflict of interest. References:

1. Aleksandrov A. A. (2004). Psihoterapiya: uchebnoe posobie. 480 p.

2. Burlachuk L. F. (2012). Psihoterapiya : uchebnik dlya vuzov. L. F. Burlachuk, A. S. Kocharyan, M. E. Zhidko. 496 p. [in Russian].

3. Bek Dzh. S. (2006). Kognitivnaya terapiya : polnoe rukovodstvo. Dzhudit Bek. 400 p. [in Russian].

4. ManIlov I. F. (2015). Psihoterapevtichna konfrontatsIyna sugestIya : bazovi polozhennya I. F. ManIlov. AktualnI problemi psihologIYi : ZbIrnik naukovih prats Institutu psihologiyi imeni G.S. Kostyuka NAPN UkraYini. P.III : Konsultativna psihologIya I psihoterapIya. Vipusk 11. S. 170185 [in Ukrainian].

5. ManIlov I. F. (2016). Rozvitok adaptivnogo mislennya za dopomogoyu konfrontatsiynoyi sugestiyi [Elektronniy resurs] ManIlov Igor FelIksovich. TehnologIYi rozvitku Intelektu. Rezhim dostupu:

http://www.psytir.org.ua/upload/journals/2.1/authors/2016/Manilov_Igor_Felixovich_Rozvytok_ad aptyvnogo_myslennya_za_dopomogoyu_konfrontatsijnoi_sugestii.pdf [in Ukrainian].

6. ManIlov I. F. (2016). TeoretichnI osnovi psihoterapevtichnoYi konfrontatsIynoYi sugestIYi : ratsIonalna psihoterapIya . I. F. ManIlov Problemi suchasnoYi psihologIYi : ZbIrnik naukovih prats Kam'yanetsPodIlskogo natsIonalnogo unIversitetu ImenI Ivana OgIEnka, Institutu psihologIYi ImenI G.S. Kostyuka NAPN UkraYini. Vip. 33. pp. 353-365 [in Ukrainian].

7. Holmogorova A. B. (2000). Kognitivno-bihevioralnaya psihoterapiya N. G. Garanyan // Osnovnyie napravleniya sovremennoy psihoterapii. M. : «Kogito-Tsentr», pp. 224-267 [in Russian]. 